\title{
Differential Histone Acetylation in Sub-Regions of Bed Nucleus of the Stria Terminalis Underlies Fear Consolidation and Extinction
}

\author{
Vandana Ranjan ${ }^{1}$, Sanjay Singh ${ }^{2}$, Sarfraj Ahmad Siddiqui' ${ }^{2}$ Sukanya Tripathi ${ }^{2}$, \\ Mohd Yahiya Khan ${ }^{2}$, and Anand Prakash ${ }^{2} \bowtie$ \\ ${ }^{1}$ Department of Biochemistry, Dr. R M L Avadh University, Lucknow, India \\ ${ }^{2}$ Department of Biotechnology, Babasaheb Bhimrao Ambedkar University, Lucknow, India
}

Objective The hallmark of anxiety disorders is excessive fear. Previous studies have suggested that selective neural projections from Basal nucleus of stria terminalis (BNST) to amygdala and vice-versa precisely control the fear learning process. However the exact mechanism how the BNST controls fear consolidation and its extinction is largely unknown. In the present study we observed the changes in the BNST sub-regions following fear conditioning and its extinction.

Methods The change in the number of positive neurons was determined by immunohistochemistry for Acetyl H3 (Histone 3), Acetyl H4 (Histone 4), cAMP response element binding Protein (CBP) and c-fos in three sub-regions of the BNST namely the anterio-lateral BNST (STLP) and anterio-medial BNST (STMA), and lateral-ventral BNST (STLV) of rats subjected to auditory fear conditioning and extinction.

Results We found significant increase in the number of CBP, acetyl H3 and acetyl H4 positive neurons in the STMA and STLV but not in the STLP after fear conditioning. However, following fear extinction the number of CBP, acetyl H3 and acetyl H4 positive neurons increased significantly in the STLP but not in the STMA and STLV. Similar changes were observed in the number of c-fos positive neurons after fear consolidation and extinction.

Conclusion The results from this study suggest that the differential histone acetylation in the different sub-regions of the BNST following fear learning and its extinction may be responsible for changes in the neuronal activation patterns resulting in either fear or less fear.

Psychiatry Investig 2017;14(3):350-359

Key Words Bed nucleus of the stria terminalis, Extended amygdala, Fear memory, Histone acetylation.

\section{INTRODUCTION}

The extended amygdala, comprising of the basolateral nucleus of the amygdala (BLA), central nucleus of the amygdala $(\mathrm{CeA})$, and bed nucleus of the stria terminalis (BNST), play important role in the development of fear and anxiety-like behaviors. ${ }^{1-11}$ The CeA and BNST, project to various anatomic areas involved in the development of fear or anxiety. The fibers from BLA to the BNST pass through CeA and cells in the lateral division of the CeA project to the BNST. ${ }^{12}$

\footnotetext{
Received: April 15, 2016 Revised: May 31, 2016

Accepted: July 6, 2016 Available online: March 14, 2017

$\triangle$ Correspondence: Dr. Anand Prakash

Department of Biotechnology, Babasaheb Bhimrao Ambedkar University, Vidya Vihar, Raibareli road, Lucknow 226025, India

Tel: +91-522-2505364, Fax: +91-522-2440821

E-mail: anandlohia@gmail.com

(c) This is an Open Access article distributed under the terms of the Creative Commons Attribution Non-Commercial License (http://creativecommons.org/licenses/bync/4.0) which permits unrestricted non-commercial use, distribution, and reproduction in any medium, provided the original work is properly cited.
}

There is dissociation in the role of the central amygdala (CeA) and the bed nucleus of the stria terminalis (BNST). CeA is involved in the expression of both cued and contextual fear, while BNST is involved in the expression of contextual fear only. ${ }^{13,14}$ The BNST is heterogeneous in structure, and different sub-regions within the BNST appear to make unique contributions to fear and anxiety. ${ }^{15-22}$ It shares connections with several important emotion-regulating areas in the brain, including the amygdala, dorsal raphe nucleus, hippocampus, hypothalamus, nucleus accumbens, prefrontal cortex, and ventral tegmental area. It directly influences freezing behavior via its projections to the amygdala and periaqueductal gray. ${ }^{23-33}$ Based on cytoarchitecture features, specific neuronal types and their neurochemical make-up, the BNST has been divided into anterio-lateral (BNST-AL/STLP), anterio-medial (BNSTAM/STMA) and anterio-ventral (BNST-AV/STLV) subregions. The hypothalamus-pituitary-adrenal-regulating neurons are concentrated in the ventral (BNST-AV/STLV) and 
medial (BNST-AM/STMA) portions. ${ }^{34}$ While the neurons in the dorsolateral part of the BNST-A (BNST-AL/STLP) contribute the outputs to brain stem assemblies regulating fear manifestation. ${ }^{35}$

Recent reports using techniques that allow selective manipulations of different BNST regions ${ }^{18}$ or of different cell types within these regions ${ }^{17}$ show BNST to exert a dual influence over fear expression. On one hand, it maintains contextual fear; on the other, its anterolateral region (STLP), wields an inhibitory influence over fear output networks. The inhibition of STLP neurons results in activation of CeM and increase in the c-fos expression. ${ }^{36-41}$ Moreover, Duvarci et al. ${ }^{42}$ have shown that the increased activity in the BNST during fear conditioning, may be responsible for the decreased cue selectivity in the amygdala. The existence of this dual effect on the fear circuitry has been attributed to regional difference in the activity of BNST- STLP and STMA in relation to learned fear. ${ }^{43}$ However, the exact molecular mechanism underlying this differential activity in the subdivisions of BNST is not well defined. Recently BNST has also been found to be critical for the reinstatement of extinguished fear after fear extinction. ${ }^{44}$ Overall in light of these current findings it seems likely that although the BNST plays a major role in context selectivity during fear learning, it also influences the cued learning and its extinction. Till date any direct role of BNST in cued fear consolidation/ extinction lies unexplored.

Recent findings suggest that histone acetylation, is an essential and broadly utilized mechanism for fear consolidation, reconsolidation, maintenance, and extinction. ${ }^{45-49}$ We speculated that the differential histone acetylation in the sub regions of the BNST might be responsible for the regional differences in the activity observed in BNST leading to differential fear outputs. Pavlovian fear conditioning and extinction in rodents provides a clinically relevant model to explore the behavioral and brain mechanisms operant during fear learning and extinction..$^{50-53}$

In the present study we explore this possibility by combining auditory fear conditioning/extinction, and analysis of cfos expression patterns as a neuronal activity marker along with that of CBP a histone acetyl transferase (HAT) and acetylation of $\mathrm{H} 3$ and $\mathrm{H} 4$ in the sub regions of BNST. We gauged the changes in histone acetylation in regulation of differential activity within sub regions of BNST, following fear consolidation and extinction in rats.

\section{METHODS}

\section{Animals}

Experiments were conducted on SD (Sprague Dawley) rats (250-300 g) housed individually under standard conditions on a 12 -h light/dark cycle, temperature maintained at $23^{\circ} \mathrm{C}$ and water and food were available ad libitum. Rats were handled for one week before the experiment. All experiments were carried out under strict compliance with Committee for the Purpose of Control and Supervision of Experiments on Animals, Ministry of Environment and Forests, Government of India (Approval number 853/AC/04/ CPCSF).

\section{Behavioral procedures}

\section{Fear conditioning}

After exposing to context A for 3 minutes, rats were fear conditioned in the context A (a transparent Plexiglas chamber with metal grids that was cleaned before each session with 70\% ethanol) (V. J. Instruments). Conditioning involved 5 pairings of the Conditioned Stimulus (CS, total duration $10 \mathrm{~s}$, $1 \mathrm{~Hz}$ tone, $80 \mathrm{~dB}$ ) with the Unconditioned Stimulus ( US, $1 \mathrm{~s}$ foot-shock $0.7 \mathrm{~mA}$, inter-trial interval: $60 \mathrm{~s}$ ). The US co-terminated with the CS. The freezing was used to measure the conditioned fear response and was defined as cessation of all movement with exception of respiration and non-awake and rest body procedure. ${ }^{54,55}$ Freezing was videotaped and later scored offline by recording the total time spent during 10 -second tone CS. In addition freezing was assessed from overhead video tracking device (V.J. instruments, India). The data was converted to freezing values using software where freezing was defined as continuous inactivity lasting for at least 2 seconds. The values were then transformed to freezing percentage and used exclusively to match groups after conditioning. After experiment, animals were replaced back to their home cages. A naïve control group was included which had no exposure to the experimental conditions. Conditioned groups $(n=8)$ were sacrificed 2 hours after experiment.

\section{Fear extinction}

Fear conditioning, especially the presence or absence of inhibition or extinction of learned fear, ${ }^{56}$ is used to study recurring and re-experiencing symptoms of post-traumatic stress disorder (PTSD) in both humans and animal models. ${ }^{57,58}$ One group of conditioned rats $(n=8)$ underwent extinction 24 hours after fear training. Extinction training involved training in the context B (a black-stripped non-transparent Plexiglas chamber with a planar floor that was cleaned before each session with vanilla essence) (V. J. Instrument). Freezing behavior was measured as described above. Animals received 30 presentations of the CS (total duration $10 \mathrm{~s}, 1 \mathrm{~Hz}$ tone, 80 $\mathrm{dB}$, inter-trial interval: $10 \mathrm{~s}$ ) without presentation of US. After 2 hours extinction, animals ( $n=8$ per group) were sacrificed for immunohistochemical analysis. Another group of agematched animals that were handled by the experimenter but 
did not receive any experimental manipulations were used as naive controls in all experiments.

Retention test was performed 24 hours the conditioned and extinction groups along with the control by presentation of the CS (5 tones, total duration $10 \mathrm{~s}, 1 \mathrm{~Hz}$ tone, $80 \mathrm{~dB}$, intertrial interval: $10 \mathrm{~s}$ ) in context $\mathrm{B}$. The animals, which were used for IHC, did not undergo retention test.

\section{Tissue preparation for immunohistochemistry}

Rats were anesthetized with pentobarbital (40 mg/kg, i.p.) and transcardially perfused with chilled normal saline, followed by ice-cold 4\% paraformaldehyde in $0.1 \mathrm{M}$ phosphate buffer, $\mathrm{pH}$ 7.4. Animals were decapitated and brains were removed and post fixed in 4\% paraformaldehyde in Phosphate Buffer for 24 hours and then cryoprotected in 10\%, 20\% followed by $30 \%$ sucrose solution (in $0.1 \mathrm{M}$ phosphate buffer, $\mathrm{pH}$ 7.4). Brains were then frozen in at $-35^{\circ} \mathrm{C}$ for 30 mins and kept at $-80^{\circ} \mathrm{C}$ until sectioning. Coronal sections $20 \mu \mathrm{m}$ thick were obtained by sectioning with a cryostat (Microm HM 525, Germany).

\section{Immunohistochemistry}

Immunostaining was performed on free-floating $20 \mu \mathrm{m}$ coronal brain sections containing BNST regions from different groups serially collected for each antibody in order to have matching sections for each antibody from each group (Bregma $0.12 \mathrm{~mm}$ up to -0.12 , Interaural $9.00 \mathrm{~mm}$ ). In brief the sections were washed and blocked in PBS containing 1\% normal horse serum (NHS Vectastain Elite ABC kit, Vector Laboratories, Burlingame, CA, USA), 0.25\% tween 20. These brain slices were then incubated overnight at room temperature in antiAcetyl H3K9, anti-Acetyl H4K5, anti-c-fos and anti-CBP primary antibodies (rabbit monoclonal, 1:1000, 1:500, 1:500, 1:1000 dilution respectively, Abcam) overnight. Sections were then incubated with a biotinylated secondary antibody (anti-rabbit IgG, 1:500 dilution, Vecta-stain Elite ABC kit,

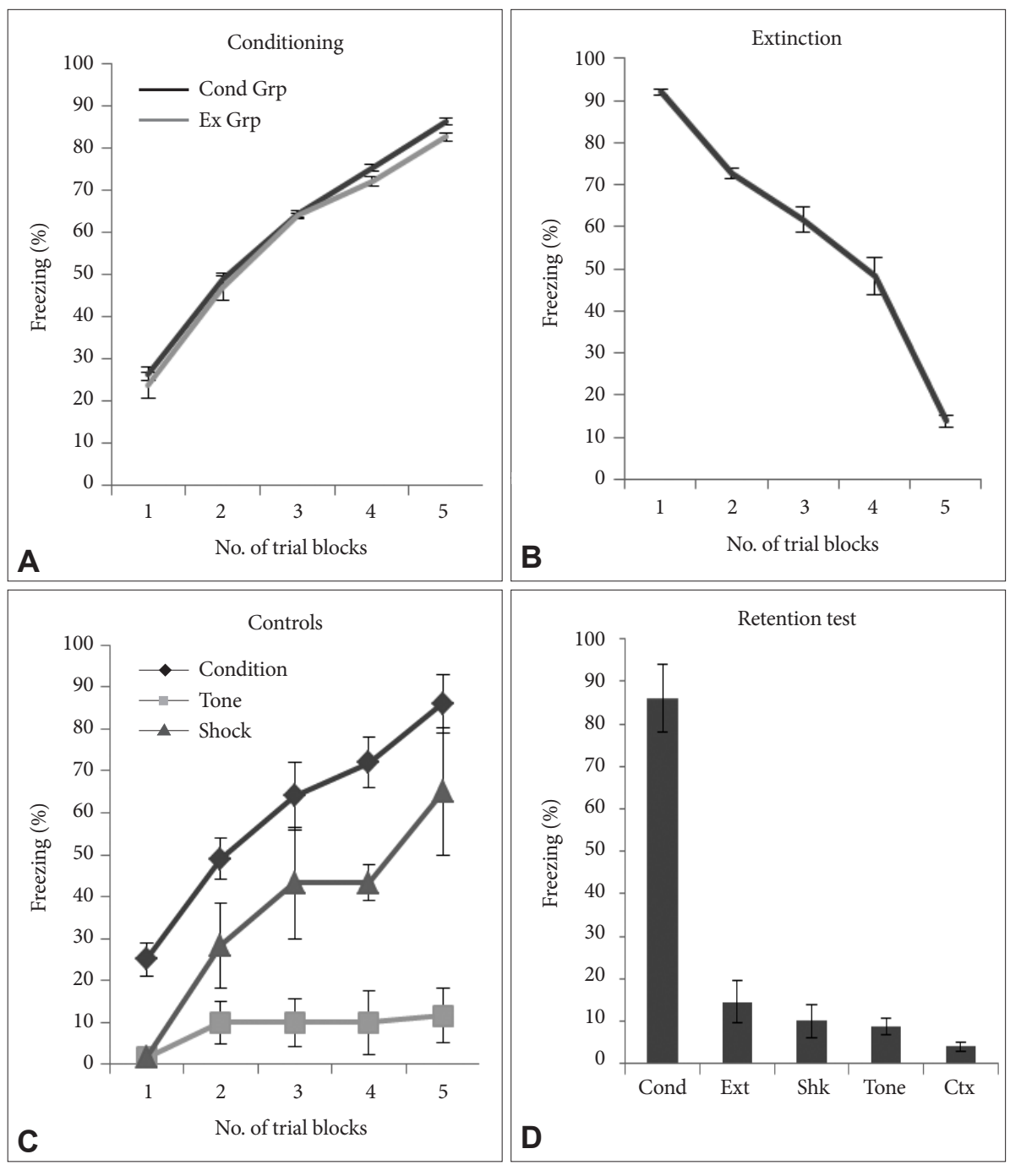

Figure 1. Freezing behavioral. A: During conditioning, there was increase in the freezing behavior both in conditioned as well as extinction groups. B: During extinction training there was attenuation in \% freezing across the trials and very low level of freezing was observed in the last trial as compared with the first trial. C: Percent freezing in control groups, shock only and tone only along with conditioned group. D: Percent freezing during retention test across all the groups $\left({ }^{*} p<0.05\right)$. All data are presented as means \pm SEM (Cond GrpConditioning group, Ext Grp- Extinction group, Cond- Condition, Ext- Extinction, Shk- Shock, Ctx- Context). 
Vector Laboratories, Burlingame, CA, USA) for $2 \mathrm{~h}$ at room temperature followed by Vecta-Stain Elite ABC kit (Vector Laboratories) followed by DAB staining (DAB peroxidase substrate, Vector laboratories). Sections were mounted and Images of the sections were acquired from at least three sections per rat using the NS-BR image analysis software from Nikon. Expression was analyzed as number of positive nuclei in BNST region of the rat brain. Number of positive neurons was counted using the Nis-BasicResearch image analysis system (Nikon, Tokyo) attached to a Nikon Eclipse Ni microscope (Nikon, Tokyo, Japan).

\section{Statistical analysis}

All behavioral data are expressed as means and standard error of the means ( \pm SEM, a measure of the statistical accuracy of an estimate, equal to the standard deviation of the theoretical distribution of a large population of such estimates) and were analyzed with one-way analysis of variance (ANOVA). For each conditioning session, the freezing data were transformed to a percentage of observations. Student t-test was used to compare freezing score. The number of Acetyl H3K9, Acetyl H4K5, CBP and c-fos immuno-positive neurons was analyzed separately in STMA, STLP and STLV using independent one-way ANOVAs for each brain structure. Post-hoc comparisons in the form of Bonferroni tests were performed after a significant overall $\mathrm{F}$ ratio.

\section{RESULTS}

\section{Fear conditioning and extinction}

There was significant increase in the freezing behavior across the conditioning session $(\mathrm{p}<0.001)$ with no significant difference in the freezing across the groups ( $p>0.05)$. During conditioning significant increase in the level of freezing was observed across the trials and last trial showing robust freezing as compared to first trial $(\mathrm{p}<0.001, \mathrm{t}=30.15)$ (Figure 1A). After 24 hours the rats underwent fear extinction. During extinction training, all rats exhibited similar attenuation in freezing across the trials and significantly lower freezing was observed in the last trial as compared with the first trial $(\mathrm{p}<$



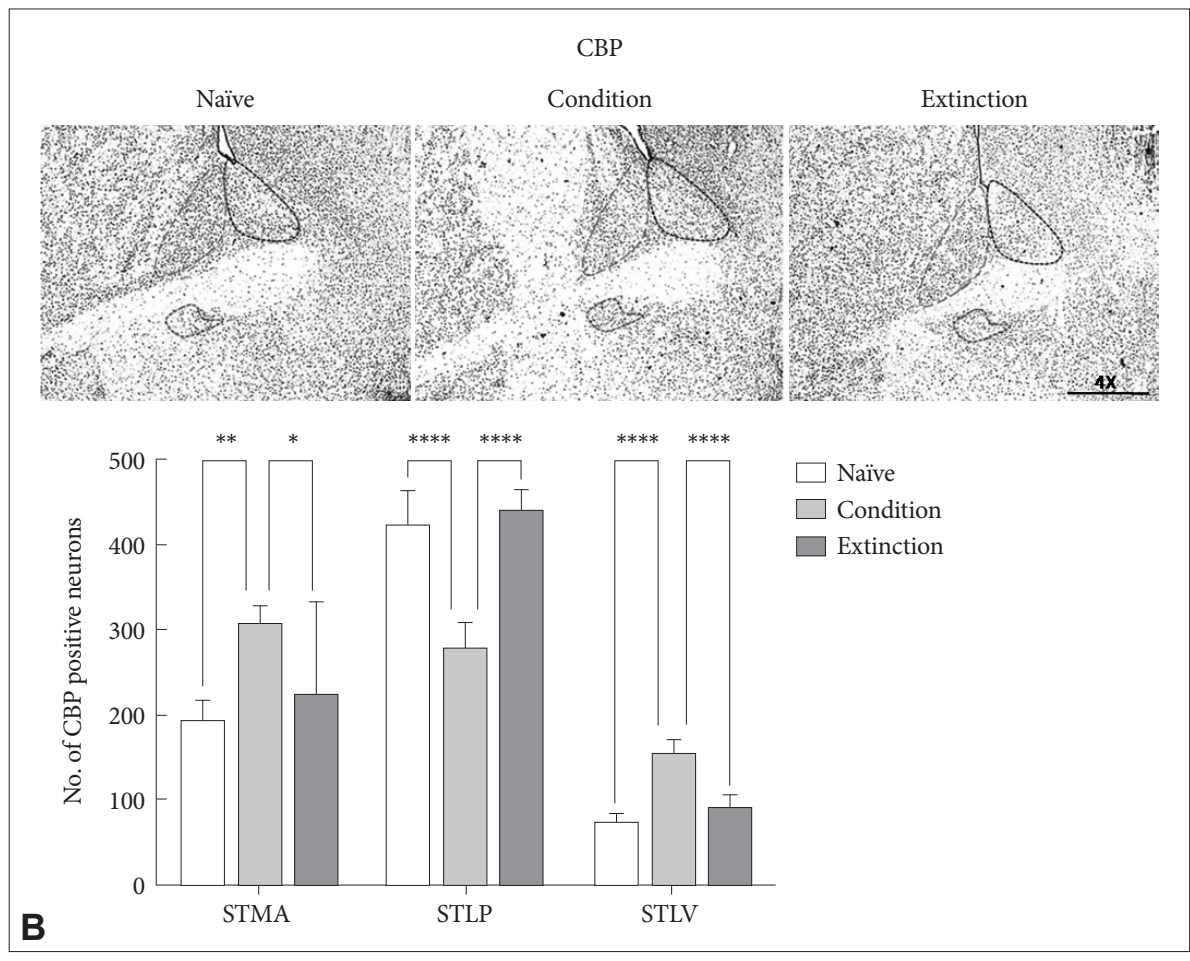

Figure 2. A: Diagrammatical representation of BNST subnuclei (STLP-BNST lateral-posterior, STLV-BNST lateral-ventral, STMA-BNST medial-anterior). B: Represents CBP positive neurons expression in BNST region following conditioning and extinction (CBP- CREB binding protein). 
0.001, $\mathrm{t}=41.44$ ) (Figure 1B). There was significant difference in the $\%$ freezing observed between initial and final trials in both the conditioned group as well as extinction group $(\mathrm{p}<$ $0.001, t=33.74)$. Freezing was measured in all the control groups (Figure 1C). All control groups had significantly lower freezing compared to the freezing observed in the conditioning group in each trial. Retention test for memory was performed for all groups (Figure 1D). Conditioning group showed robust freezing compared to all groups during retention testing.

\section{CREB Binding protein (CBP) in the sub-regions of BNST}

CBP, a histone acetyl transferase, has been attributed to the active transcription during neuronal activation. ${ }^{59}$ The number of CBP positive neurons in the sub-regions of the BNST was counted following fear conditioning and fear extinction in rats. Fear conditioning resulted in significant increase in the number of CBP positive neurons in the STMA [p $<0.01, \mathrm{~F}(2$, $21)=6.833]$, and STLV $[\mathrm{p}<0.0001, \mathrm{~F}(2,21)=69.15]$ but not in the STLP [ $p>0.05, F(2,21)=63.81]$ as compared to the naive control and extinction group. Similarly there was significant increase in the acetylation of CBP in the STMA [ $p<0.05 ; \mathrm{F}$ (2, $21)=6.833]$ and STLV $[\mathrm{p}<0.0001 ; \mathrm{F}(2,21)=69.15]$; but not in the STLP as compared to the extinction group. However, extinction of the conditioned fear resulted in significant increase in the level of CBP positive neurons in the STLP [p< $0.0001, F(2,21)=63.81]$ and significant decrease in the STLV $[\mathrm{p}<0.0001, \mathrm{~F}(2,21)=69.15]$ as compared to the conditioned group. No significant change was observed in STMA [p> $0.05, \mathrm{~F}(2,21)=6.833$ ] as compared to condition group. There was no significant change in the STMA $(p>0.05)$ and STLV ( $p>0.05$ ) as compared to the naïve control (Figure $2 B$ ).

\section{Acetyl $\mathrm{H} 3$ and $\mathrm{H} 4$ in the sub-regions of BNST}

Our next step was to look at the effect of fear consolidation and extinction on Histone $\mathrm{H} 3$ and $\mathrm{H} 4$ acetylation in these sub-regions (Figure 2A).

Fear memory consolidation led to significant increase in the acetylation of H3K9 in the STMA [p $<0.001, \mathrm{~F}(2,21)=$ 12.10] and STLV $[\mathrm{p}<0.01, \mathrm{~F}(2,21)=11.46]$ with no significant changes in the STLP as compared to the naïve control ( $>0.05)$. Similarly there was significant increase in the acetylation of H3K9 in the STMA $[\mathrm{p}<0.01 ; \mathrm{F}(2,21)=12.10]$ and STLV $[\mathrm{p}<0.01, \mathrm{~F}(2,21)=11.46]$; but not in the STLP as compared to the extinction group. However extinction of the fear resulted in significant elevation in the number of acetyl H3K9 positive neurons in the STLP $[\mathrm{p}<0.0001, \mathrm{~F}(2,21)=47.31]$ when compared to the condition group/ naïve control and there was no significant change in the number of acetyl H3K9 in the STMA and STLV following extinction as compared to the naive control (Figure 3).

The change in the acetyl H4K5 level was similar to that of acetyl $\mathrm{H} 3 \mathrm{~K} 9$. Conditioning training resulted in increase in the acetyl $\mathrm{H} 4$ positive neurons in the STMA [p $<0.0001, \mathrm{~F}(2$, $21)=47.18]$ and STLV $[\mathrm{p}<0.01, \mathrm{~F}(2,21)=12.83]$ region of the BNST in compare with naive control but no significant change was observed in the STLP ( $p>0.05)$. The extinction of the con-

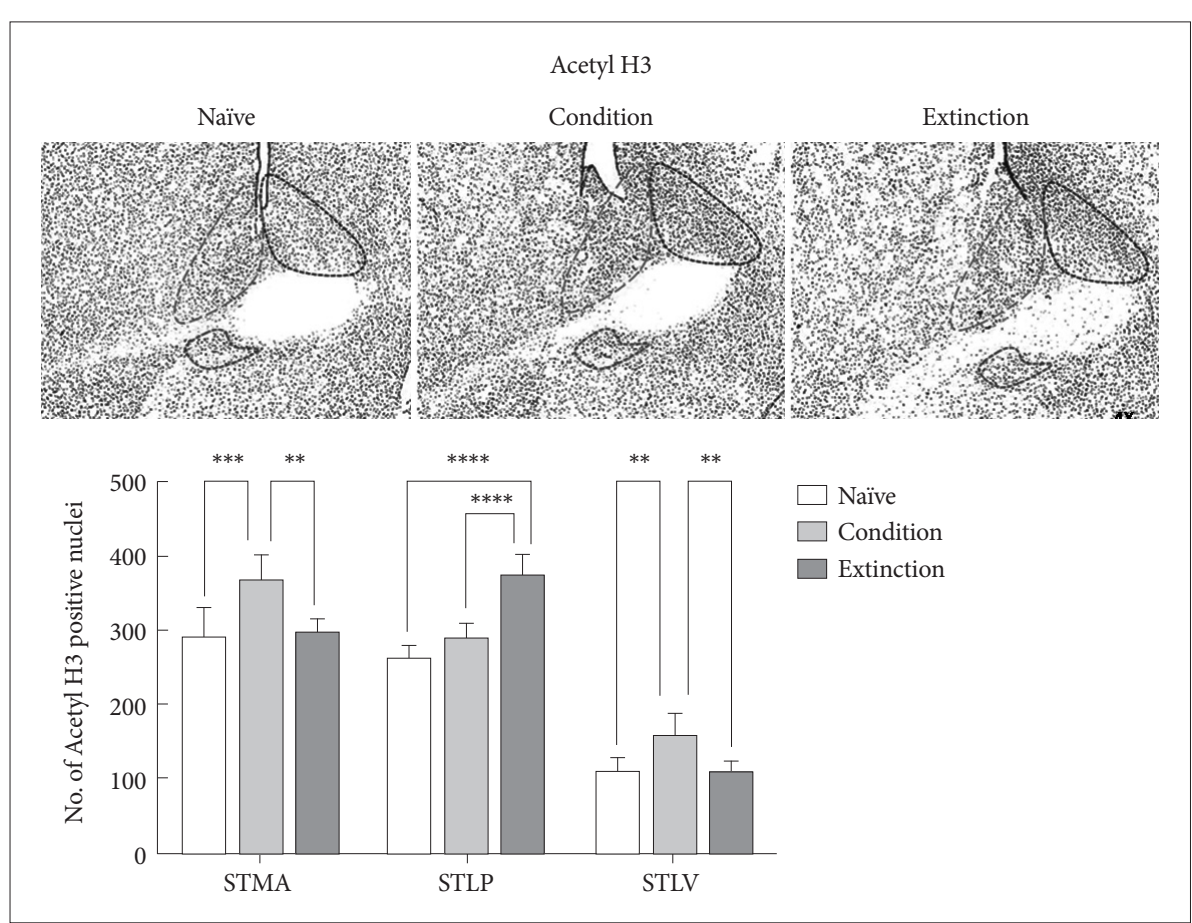

Figure 3. Represents Acetyl $\mathrm{H} 3$ positive neurons expression in BNST region following conditioning and extinction (STLPBNST lateral-posterior, STLV-BNST lateral-ventral, STMA-BNST medial-anterior). 
ditioned fear resulted in increased Acetyl $\mathrm{H} 4$ level in the STLP $[p<0.001, F(2,21)=12.52]$ region of the BNST but not in the STMA ( $>0.05)$ and STLV ( $>0.05)$ region as compared to the naïve control (Figure 4 ). Similarly extinction of the conditioned fear resulted in increased Acetyl $\mathrm{H} 4$ level in the STLP $[\mathrm{p}<0.01, \mathrm{~F}(2,21)=12.52]$ region of the BNST as compared to the conditioned group and significant decrease in the STMA $(\mathrm{p}<0.0001)$ and STLV $(\mathrm{p}<0.001)$ region as compared to the conditioned group. Extinction group shows significant changes with conditioned group in H4K5 level in STLP region $[\mathrm{p}<0.05, \mathrm{~F}(2,21)=12.52]$.

\section{c-fos in the subregions of BNST}

As it is well known that there is a strong correlation be-

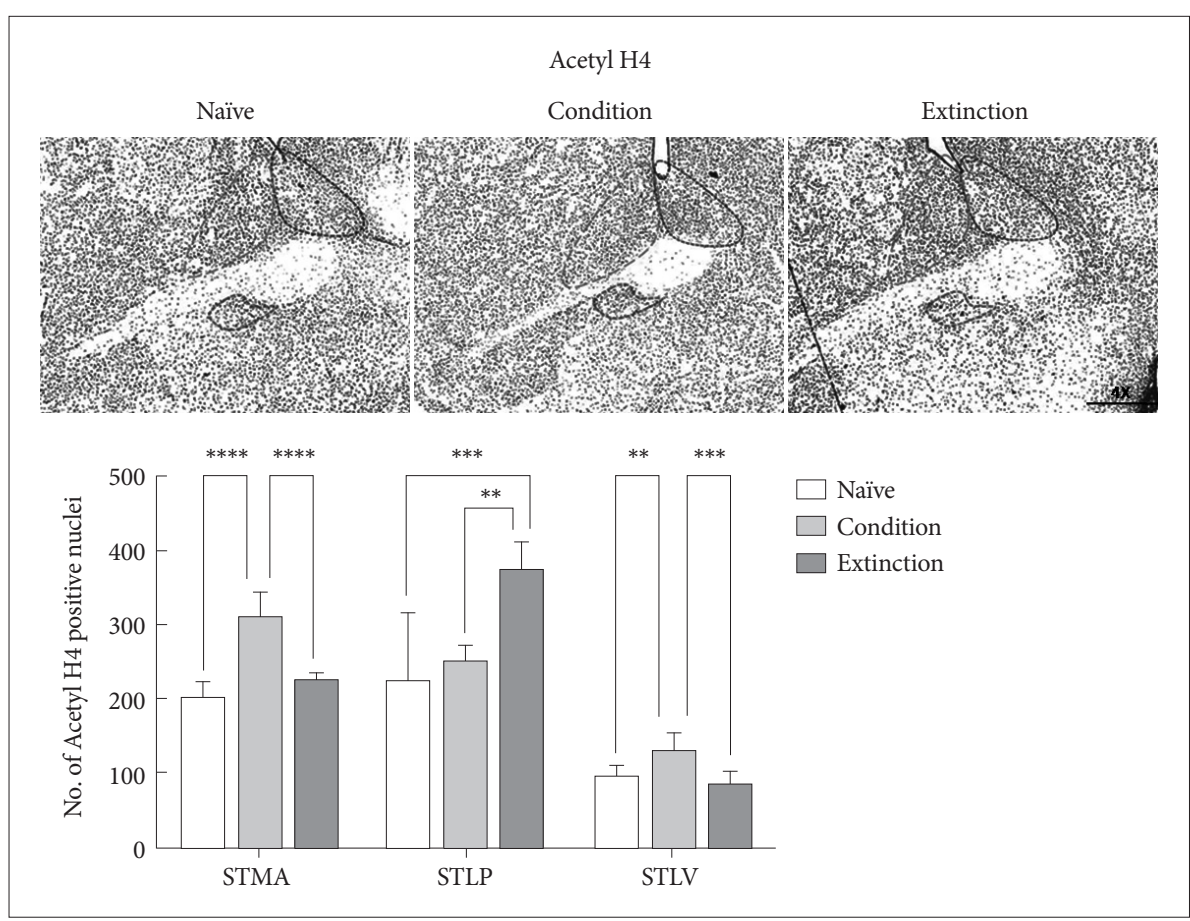

Figure 4. Represents Acetyl $\mathrm{H} 4$ positive neurons expression in BNST region following conditioning and extinction (STLPBNST lateral-posterior, STLV-BNST lateral-ventral, STMA-BNST medial-anterior).

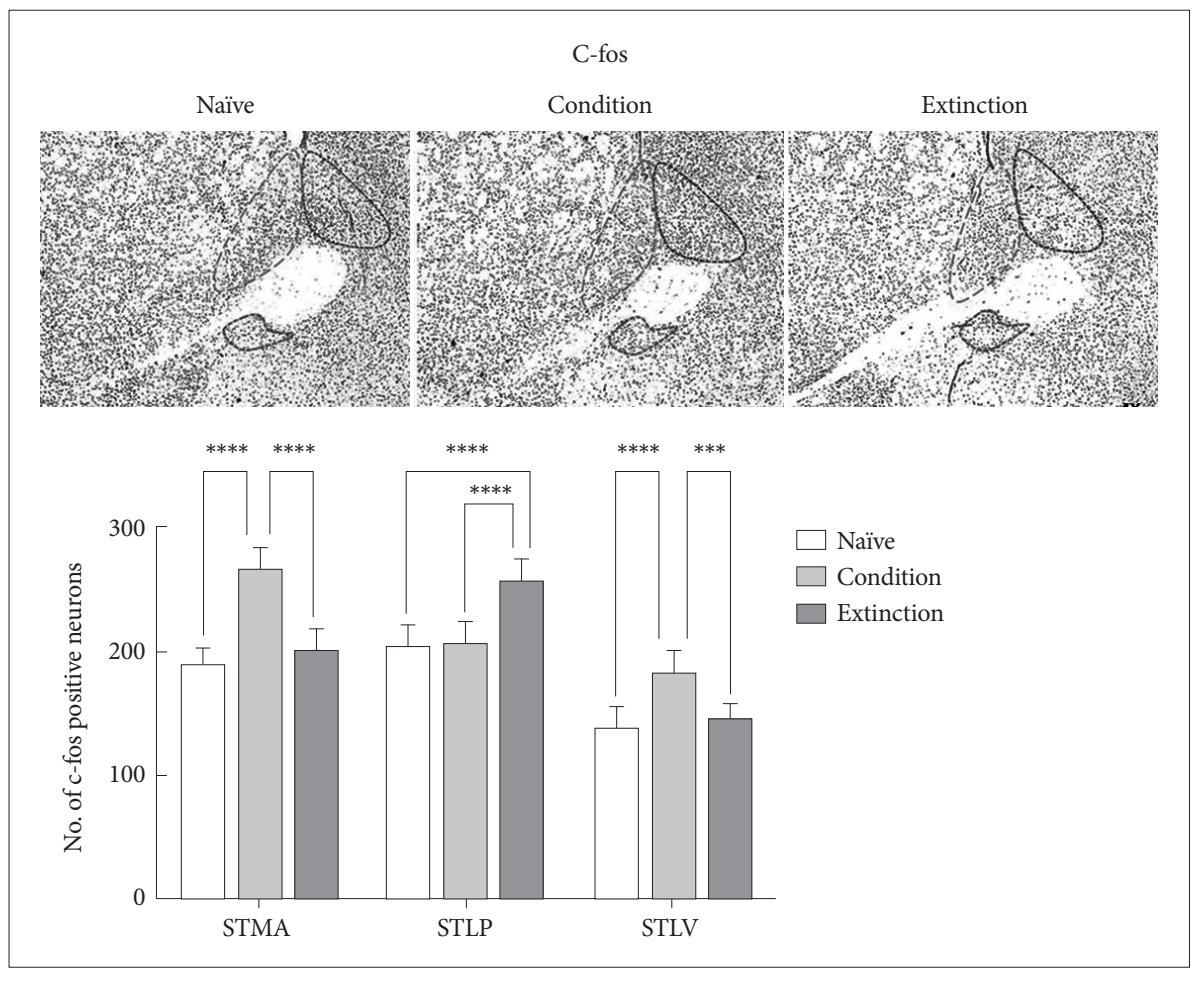

Figure 5. Represents c-fos positive neurons expression in BNST region following conditioning and extinction (STLPBNST lateral-posterior, STLV-BNST lateral-ventral, STMA-BNST medial-anterior). 
tween transcriptional activity and acetylation of the histone $\mathrm{H} 3$ and $\mathrm{H} 4$ lysine residues, ${ }^{60}$ we next looked at c-fos, an immediate early gene and a marker for neuronal activity in a region. It was found that the increase/decrease in the level of c-fos in the STMA, STLV and STLP of BNST following fear conditioning and its extinction was similar to the $\mathrm{H} 3 / \mathrm{H} 4$ acetylation and paralleled to changes in the level of CBP, Acetyl $\mathrm{H} 3$ and Acetyl H4. Conditioning resulted in increase in the number of $\mathrm{c}$-fos positive neurons in the STMA [p $<0.0001, \mathrm{~F}$ $(2,21)=41.56]$ and STLV $[\mathrm{p}<0.0001, \mathrm{~F}(2,21)=12.83]$ but not in the STLP. Extinction resulted in significant increase in the number of $\mathrm{c}$-fos positive neurons in the STLP [p $<0.0001, \mathrm{~F}$ $(2,21)=12.52$ ] but not in the STLV and STMA as compared to the naivve control (Figure 5). Similarly extinction of the conditioned fear resulted in increase in the no. of c-fos positive neurons in the STLP $[\mathrm{p}<0.0001, \mathrm{~F}(2,21)=19.88]$ region of the BNST as compared to the conditioned group and significant decrease in the STMA $(p<0.0001)$ and STLV $(p<0.001)$ region as compared to the conditioned group. Extinction group shows significant changes with conditioned group in c-fos level in STLP region [ $\mathrm{p}<0.001, \mathrm{~F}(2,21)=12.52]$.

\section{DISCUSSION}

The present study was undertaken to shed light on how that different sub-regions of BNST respond differentially to the fear memory consolidation and its extinction. Interestingly, there was region specific activation in the BNST sub regions following fear consolidation and extinction. The differential activity as evident by the changes in the expression of the immediate early gene $\mathrm{c}$-fos paralleled to the changes in the histone $(\mathrm{H} 3 / \mathrm{H} 4)$ acetylation patterns in these regions.

Fear conditioning model used in the present study is an extensively used model for associative learning in rats. ${ }^{61}$ The freezing levels in both the conditioned and extinction groups are consistent with earlier studies. There was consequent increase and reduction in \% freezing observed in the present study during fear acquisition and extinction training respectively. ${ }^{62-65}$ The conditioning group retained maximum freezing while the extinction group as well as naive control retained least fear levels when tested 24 hours after the training.

The BNST is a collection of nuclei and different BNST regions form contrasting connections. ${ }^{22}$ The ventral BNST-AV/ STLV and medial BNST-AM/STMA portions have mainly hypothalamus-pituitary-adrenal-regulating neurons ${ }^{6,9}$ while BNST-AL/STLP neurons contribute most BNST outputs to brain stem structures regulating fear expression. ${ }^{66,67}$ In the present study we investigated the role of BNST, in regulating fear learning and extinction. We looked at the changes in STMA, STLP and STLV of the BNST through immunohisto- chemistry for CBP, Acetyl H3/H4 and c-fos following fear conditioning and extinction. These sub-regions showed different neuronal activation patterns after fear conditioning and extinction. The heterogeneous projections from amygdala and the intrinsic BNST network especially the GABArgic inputs from $\mathrm{CeA}$ and glutamatergic inputs from $\mathrm{BLA}^{68,69}$ to these regions exert opposite influences on fear response. A recent study has shown that the projections from STLP to STMA and STLV are purely inhibitory. On activation the STLP via these inhibitory projections tends to reduce the activity in STMA and STLV neurons. On other hand a reduction in STLP activity results in positive feedback effect where disinhibition from STMA to STLP inputs increase the return inhibitory connections leading to further disinhibition of STMA neurons. ${ }^{70}$ Our findings indicate that following fear learning the activity is higher in STMA and STLV but not in STLP as evident by the c-fos positive neurons. Similarly following extinction there was an increase in the activity of STLP neurons but not of STMA and STLV. This may be due to the reciprocal inhibitory control of these sub-regions on each other.

Regulation of chromatin structure is one of the fundamental molecular mechanisms contributing to long-term memory formation. The stabilization of normal and pathological fear memories involves distinct phases that are dependent on regionally and temporally distinct epigenetic mechanisms. ${ }^{71-73}$ It has also been suggested that the functional and mechanistic outcomes of epigenetic marks differ according to the brain region and the stage of memory formation. In this study we found that the neuronal activation paralleled to the changes in histone acetylation and also to that of CBP, a histone acetyl transferase. CBP and p300 are large multidomain proteins that possess intrinsic histone acetyltransferase (HAT) activity. It has been shown that CBP is critical for the in vivo acetylation of lysines on histones H2B, H3, and H4. CBP's homolog p300 is unable to compensate for the loss of CBP function in knockouts. ${ }^{74,75}$ Glen Schafe's group has shown that cued fear conditioning is associated with increased expression of acetylated histone $\mathrm{H} 3$ in the lateral amygdala. ${ }^{76}$ Moreover acetylation of lysine 5 on $\mathrm{H} 4$ increases in the hippocampal region following contextual fear conditioning. ${ }^{77}$

The STMA and STLV were active during conditioning and the STLP following extinction training. Several studies have shown that stimuli, which usually induce activity-dependent gene transcription, lead to an increase in histone acetylation at the c-fos promoter as well as other activity-regulated gene promoters. ${ }^{78,79}$ To date, the majority of studies examining the requirement of these HATs in memory processes have focused on p300/CBP using knock-out models in the context of hippocampal-dependent memory paradigms, including object recognition, spatial memory, and contextual fear 
memory. ${ }^{80-87}$ In the present study we observed the histone acetylation pattern in sub regions of BNST following conditioning and extinction.

Overall, there was increase in the level of CBP, Acetyl H3/ $\mathrm{H} 4$ and $\mathrm{c}$-fos in the STMA following fear conditioning as compared to the naïve control. This is consistent with earlier reports which have shown that the CS responsiveness of the STMA neurons is similar to that of $\mathrm{CeM},{ }^{88,89}$ both having innervations from prelimbic cortex (PL), a region playing an active role in fear acquisition. ${ }^{90,91}$ However, there was an increase in the levels CBP, Acetyl H3/H4 and c-fos in the STLP but not in the STMA and STLP following extinction as compared to the conditioned group and naïve control. It is well known that the activation of STLP neurons, which are mostly GABAergic, results in inhibition of CeA. In earlier studies by our group and others it has been shown that extinction results in inhibition of the CeA neurons. ${ }^{92}$ It has also been shown through electrophysiological studies that potentiation of GABAergic neurons of STLP, ${ }^{19}$ results in startle enhancement due to the inhibition of STLP neurons and consequent disinhibition of CeA. This means that the inhibition and dis-inhibition of STLP has an important role to play in fear response and fear extinction. Our results suggest towards the existence of such a mechanism where the STLP is acting as a buffer controlling both the freezing as well as the inhibition of $\mathrm{CeA}^{93-94}$ Overall there was increase in the acetylation of $\mathrm{H} 3 / \mathrm{H} 4$ in STMA during conditioning and in STLP during extinction are in line with earlier studies which have shown that the STLP and STMA exert opposite influence on fear output network. ${ }^{22}$ Our observation that correlated the acetylation levels to the neuronal activation in STMA, STLV following conditioning and in STLP following extinction which may be indirectly responsible for the opposite effects.

In this study the histone acetylation paralleled to region specific neuronal activation in the BNST following fear memory consolidation and its extinction. The changes observed following fear consolidation and extinction may be the outcome of differential activity in the sub-regions of the BNST, which in turn may be under epigenetic control. CBP, a HAT, enhanced the acetylation of $\mathrm{H} 3$ and $\mathrm{H} 4$ and the neuronal activation as evident by $\mathrm{c}$-fos levels positively correlated to the Histone acetylation. In other words the epigenetics might be playing an important role in buffering the behavioral outcomes by differentially controlling the expression and thus the neuronal activation in the sub-regions of the BNST. Our findings represent the first comprehensive look at the role of $\mathrm{CBP} /$ HAT activity in BNST-dependent learning and memory and associated synaptic plasticity, and make an additional contribution toward our understanding of the role of epigenetic mechanisms in the regulation of memory and synaptic plas- ticity in the mammalian brain.

\section{REFERENCES}

1. Hopkins DA, Holstege G. Amygdaloid projections to the mesencephalon, pons and medulla oblongata in the cat. Exp Brain Res 1978;32:529547.

2. Sofroniew MV. Direct reciprocal connections between the bed nucleus of the stria terminalis and dorsomedial medulla oblongata: evidence from immunohistochemical detection of tracer proteins. J Comp Neurol 1983;213:399-405.

3. Veening JG, Swanson LW, Sawchenko PE. The organization of projections from the central nucleus of the amygdala to brainstem sites involved in central autonomic regulation: a combined retrograde transport-immunohistochemical study. Brain Res 1984;303:337-357.

4. Holstege G, Meiners L, Tan K. Projections of the bed nucleus of the stria terminalis to the mesencephalon, pons, and medulla oblongata in the cat. Exp Brain Res 1985;58:379-391.

5. Dong H, Petrovich GD, Swanson LW. Organization of projections from the juxtacapsular nucleus of the BST: a PHAL study in the rat. Brain Res 2000;859:1-14.

6. Dong HW, Petrovich GD, Watts AG, Swanson LW. Basic organization of projections from the oval and fusiform nuclei of the bed nuclei of the striaterminalis in adult rat brain. J Comp Neurol 2001;436:430-455.

7. Dong HW, Swanson LW. Projections from the rhomboid nucleus of the bed nuclei of the striaterminalis: implications for cerebral hemisphere regulation of ingestive behaviors. J Comp Neurol 2003;463:434472.

8. Dong HW, Swanson LW. Projections from bed nuclei of the striaterminalis, posterior division: implications for cerebral hemisphere regulation of defensive and reproductive behaviors. J Comp Neurol 2004; 471:396-433.

9. Dong HW, Swanson LW. Projections from bed nuclei of the stria terminalis, anteromedial area: cerebral hemisphere integration of neuroendocrine, autonomic, and behavioral aspects of energy balance. J Comp Neurol 2006;494:142-178.

10. Dong HW, Swanson LW. Projections from bed nuclei of the stria terminalis, magnocellular nucleus: implications for cerebral hemisphere regulation of micturition, defecation, and penile erection. J Comp Neurol 2006;494:108-141.

11. Dong HW, Swanson LW. Projections from bed nuclei of the stria terminalis, dorsomedial nucleus: implications for cerebral hemisphere integration of neuroendocrine, autonomic, and drinking responses. J Comp Neurol 2006;494:75-107.

12. Davis M, Shi C. The amygdala. Curr Biol 2000;10:R131.

13. Sullivan GM, Apergis J, Bush DE, Johnson LR, Hou M, Ledoux JE. Lesions in the bed nucleus of the striaterminalis have been shown to disrupt the freezing responses elicited by a contextual but not by a specific cue-conditioned fear stimulus. Neuroscience 2004;128:7-14.

14. Walker DL, Toufexis DJ, Davis M. Role of the bed nucleus of the striaterminalis versus the amygdala in fear, stress, and anxiety. Eur J Pharmacol 2003;463:199-216.

15. Dong HW, Petrovich GD, Swanson LW. Topography of projections from amygdala to bed nuclei of the striaterminalis. Brain Res Brain Res Rev 2001;38:192-246.

16. Kim J, Song B, Hong I, Kim J, Lee J, Park S, et al. Reactivation of fear memory renders consolidated amygdala synapses labile. J Neurosci 2010;30:9631-9640.

17. Jennings JH, Sparta DR, Stamatakis AM, Ung RL, Pleil KE, Kash TL, et al. Distinct extended amygdala circuits for divergent motivational states. Nature 2013;496:224-228.

18. Kim SY, Adhikari A, Lee SY, Marshel JH, Kim CK, Mallory CS, et al. Diverging neural pathways assemble a behavioural state from separable features in anxiety. Nature 2013;496:219-223.

19. Stephan H, Andy OJ. Quantitative comparisons of brain structures 
from insectivores to primates. Am Zool 1964;4:59-74.

20. de Olmos J, Hardy H, Heimer L. Amygdala. In: Paxinos G, Editor. The Rat Nervous System. Sydney; Academic Press, 1985, p. 317-323.

21. Ju G, Swanson LW. Studies on the cellular architecture of the bed nuclei of the striaterminalis in the rat: I. Cytoarchitecture. J Comp Neurol 1989;280:587-602.

22. Moga MM, Saper CB, Gray TS. Bed nucleus of the stria terminalis: cytoarchitecture, immunohistochemistry, and projection to the parabrachial nucleus in the rat. J Comp Neurol 1989;283:315-332.

23. Swanson LW, Cowan WM. An autoradiographic study of the organization of the efferent connections of the hippocampal formation in the rat. J Comp Neurol 1977;172:49-84.

24. Weller KL, Smith DA. Afferent connections to the bed nucleus of the stria terminalis. Brain Res 1982;232:255-270.

25. Phelix CF, Liposits Z, Paull WK. Serotonin-CRF interaction in the bed nucleus of the striaterminalis: a light microscopic double-label immunocytochemical analysis. Brain Res Bull 1992;28:943-948.

26. Sun N, Cassell MD. Intrinsic GABAergic neurons in the rat central extended amygdala. J Comp Neurol 1993;330:381-404

27. Fendt M, Endres T, Apfelbach R. Temporary inactivation of the bed nucleus of the striaterminalis but not of the amygdala blocks freezing induced by trimethylthiazoline, a component of fox feces. J Neurosci 2003;23:23-28.

28. Jalabert M, Aston-Jones G, Herzog E, Manzoni O, Georges F. Role of the bed nucleus of the striaterminalis in the control of ventral tegmental area dopamine neurons. Prog Neuropsychopharmacol Biol Psychiatry 2009;33:1336-1346.

29. Crestani CC, Alves FH, Gomes FV, Resstel LB, Correa FM, Herman $\mathrm{JP}$, et al. Mechanisms in the bed nucleus of the striaterminalis involved in control of autonomic and neuroendocrine functions: a review. Curr Neuropharmacol 2003;11:141-159.

30. Asok A, Ayers LW, Awoyemi B, Schulkin J, Rosen JB. Immediate early gene and neuropeptide expression following exposure to the predator odor 2,5-dihydro-2,4,5-trimethylthiazoline (TMT). Behav Brain Res 2013;248:85-93.

31. Avery SN, Clauss JA, Winder DG, Woodward N, Heckers S, Blackford JU. BNST neurocircuitry in humans. Neuroimage 2014;91:311-323.

32. Roman CW, Lezak KR, Hartsock MJ, Falls WA, Braas KM, Howard $\mathrm{AB}$, et al. PAC1 receptor antagonism in the bed nucleus of the striaterminalis (BNST) attenuates the endocrine and behavioral consequences of chronic stress. Psychoneuroendocrinology 2014;47:151-165.

33. Krüger O, Shiozawa T, KreifeltsB, Scheffler K, Ethofer T. Three distinct fiber pathways of the bed nucleus of the striaterminalis to the amygdala and prefrontal cortex. Cortex 2015;66:60-68.

34. Prewitt CM, Herman JP. Anatomical interactions between the central amygdaloid nucleus and the hypothalamic paraventricular nucleus of the rat: a dual tract-tracing analysis. J Chem Neuroanat 1998;15:173-185.

35. Holstege G, Bandler R, Saper CB. The emotional motor system. Prog Brain Res 1996;107:3-6.

36. Sullivan GM, Apergis J, Bush DE, Johnson LR, Hou M, Ledoux JE. Lesions in the bed nucleus of the striaterminalis disrupt corticosterone and freezing responses elicited by a contextual but not by a specific cue-conditioned fear stimulus. Neuroscience 2004;128:7-14.

37. Campeau S, Falls WA, Cullinan WE, Helmreich DL, Davis M, Watson SJ. Elicitation and reduction of fear: behavioral and neuroendocrine indices and brain induction of the immediate-early gene $c$-fos. Neuroscience 1997;78:1087-1104.

38. Sink KS, Walker DL, Yang Y, Davis M. Calcitonin gene-related peptide in the bed nucleus of the striaterminalis produces an anxiety-like pattern of behavior and increases neural activation in anxiety-related structures. J Neurosci 2011;31:1802-1810.

39. Gungor NZ, Pare D. CGRP inhibits neurons of the bed nucleus of the stria terminalis: implications for the regulation of fear and anxiety. J Neurosci 2014;34:60-65.

40. Gustafson EL, Greengard P. Localization of DARPP-32 immunoreac- tive neurons in the bed nucleus of the stria terminalis and central nucleus of the amygdala: co-distribution with axons containing tyrosine hydroxylase, vasoactive intestinal polypeptide, and calcitonin gene-related peptide. Exp Brain Res 1990;79:447-458.

41. Dobolyi A, Irwin S, Makara G, Usdin TB, Palkovits M. Calcitonin gene-related peptide-containing pathways in the rat forebrain. J Comp Neurol 2005;489:92-119.

42. Duvarci S, Bauer EP, Paré D. The bed nucleus of the stria terminalis mediates inter-individual variations in anxiety and fear. J Neurosci 2009;29:10357-10361.

43. Haufler D, Nagy FZ, Pare D. Neuronal correlates of fear conditioning in the bed nucleus of the stria terminalis. Learn Mem 2013;20:633-641.

44. Goode TD, Kim JJ, Maren S. Reversible inactivation of the bed nucleus of the stria terminalis prevents reinstatement but not renewal of extinguished fear (1,2,3). eNeuro 2015;2.

45. Bredy TW, Wu H, Crego C, Zellhoefer J, Sun YE, Barad M. Histone modifications around individual BDNF gene promoters in prefrontal cortex are associated with extinction of conditioned fear. Learn Mem 2007;14:268-276.

46. Lattal KM, Barrett RM, Wood MA. Systemic or intrahippocampal delivery of histone deacetylase inhibitors facilitates fear extinction. Behav Neurosci 2007;121:1125-1131.

47. Stafford JM, Raybuck JD, Raybinin AE, Lattal KM. Increased histone acetylation in hippocampus-infralimbic network enhances fear extinction. Biol Psychiatry 2012;72:25-33.

48. Maddox SA, Schafe GE. Epigenetic alterations in the lateral amygdala are required for reconsolidation of a Pavlovian fear memory. Learn Mem 2011;18:579-593.

49. Monsey MS, Ota KT, Akingbade IF, Hong ES, Schafe GE. Epigenetic alterations are critical for fear memory consolidation and synaptic plasticity in the lateral amygdala. PLoS One 6:e19958.

50. LeDoux JE. Emotion circuits in the brain. Annu Rev Neurosci 2000; 23:155-184.

51. Sah P, Faber ES, Lopez De Armentia M, Power J. The amygdaloid complex: anatomy andphysiology. Physiol Rev 2003;83:803-834.

52. Ehrlich I, Humeau Y, Grenier F, Ciocchi S, Herry C, Luthi A. Amygdala inhibitory circuits and the control of fear memory. Neuron 2009; 62:757-771.

53. Maren S, Quirk GJ. Neuronal signalling of fear memory. Nat Rev Neurosci 2004;5:844-852.

54. McAllister WR, McAllister DE. Behavioral Measurement of Conditioned Fear. In: Brush F, Editor. Aversive Conditioning and Learning. New York: Academic Press, 1971, p. 105-179.

55. Fanselow MS. Neural organization of the defensive behavior system responsible for fear. Psychon Bull Rev 1994;1:429-438.

56. Cannistraro PA, Rauch SL. Neural circuitry of anxiety: evidence from structural and functional neuroimaging studies. Psychopharmacol Bull 2003;37:8-25.

57. Siegmund A, Wotjak CT. Toward an animal model of posttraumatic stress disorder. Ann N Y Acad Sci 2006;1071:324-334.

58. Olsen RH, Agam M, Davis MJ, Raber J. ApoE isoform-dependent deficits in extinction of contextual fear conditioning. Genes Brain Behav 2012;11:806-812.

59. Das C, Lucia MS, Hansen KC, Tyler JK. CBP/p300-mediated acetylation of histone $\mathrm{H} 3$ on lysine 56. Nature 2009;459:113-117.

60. Pokholok DK, Harbison CT, Levine S, Cole M, Hannett NM, Lee TI, et al. Genome-wide map of nucleosome acetylation and methylation in yeast. Cell 2005;122:517-527.

61. Johnson LR, McGuire J, Lazarus R, Palmer AA. Pavlovian fear memory circuits and phenotype models of PTSD. Neuropharmacology 2012; 62:638-646.

62. Davis M, Walker DL, Myers KM. Role of the amygdala in fear extinction measured with potentiated startle. Ann N Y Acad Sci 2003;985: 218-232.

63. Maren S, Phan KL, Liberzon I. The contextual brain: implications for 
fear conditioning, extinction and psychopathology. Nat Rev Neurosci 2013;14:417-428.

64. Kim JJ, Jung MW. Neural circuits and mechanisms involved in Pavlovian fear conditioning: A critical review. Neurosci Biobehav Rev 2005; 30:182-202.

65. Myers KM, Davis M. Mechanisms of fear extinction. Mol Psychiatry 2007;12:120-150.

66. Krettek JE, Price JL. A description of the amygdaloid complex in the rat and cat with observations on intra-amygdaloid axonal connections. J Comp Neurol 1978;178:255-280.

67. McDonald AJ. Is there an amygdala and how far does it extend? An anatomical perspective. Ann NY Acad Sci 2003;985:1-21.

68. Haufler D, Nagy FZ, Pare D. Neuronal correlates of fear conditioning in the bed nucleus of the striaterminalis. Learn Mem 2013;11:633-641.

69. Graff J, Mansuy IM. Epigenetic codes in cognition and behaviour. Behav Brain Res 2008;192:70-87.

70. Jiang Y, Langley B, Lubin FD, Renthal W, Wood MA, Yasui DH, et al. Epigenetics in the nervous system. J Neurosci 2008;28:11753-11759.

71. Sweatt JD. Experience-dependent epigenetic modifications in the central nervous system. Biol Psychiatry 2009;65:191-197.

72. Oike Y, Hata A, Mamiya T, Kaname T, Noda Y, Suzuki M, et al. Truncated CBP protein leads to classical Rubinstein-Taybi syndrome phenotypes in mice: implications for a dominant-negative mechanism. Hum Mol Genet 1999;8:387-396.

73. Alarcon JM, Malleret G, Touzani K, Vronskaya S, Ishii S, Kandel ER, et al. Chromatin acetylation, memory, and LTP are impaired in $\mathrm{CBP}+/$ mice: A model for the cognitive deficit in Rubinstein-Taybi syndrome and its amelioration. Neuron 2004;42:947-959.

74. Monsey MS, Gerhard DM, Boyle LM, Briones MA, Seligsohn M, Schafe GE. A diet enriched with curcumin impairs newly acquired and reactivated fear memories. Neuropsychopharmacology 2015;40: 1278-1288.

75. Park CS, Rehrauer H, Mansuy IM. Genome-wide analysis of H4K5 acetylation associated with fear memory in mice. BMC Genomics 2013;14:539.

76. Tsankova NM, Kumar A, Nestler EJ. Histone modifications at gene promoter regions in rat hippocampus after acute and chronic electroconvulsive seizures. J Neurosci 2004;24:5603-5610.

77. Levenson JM, Sweatt JD. Epigenetic mechanisms: A common theme in vertebrate and invertebrate memory formation. Cell Mol Life Sci 2006;63:1009-1016.

78. Korzus E, Rosenfeld MG, Mayford M. CBP histone acetyltransferase activity is a critical component of memory consolidation. Neuron 2004;42:961-972.

79. Wood MA, Kaplan MP, Park A, Blanchard EJ, Oliveira AM, Lombardi TL, et al. Transgenic mice expressing a truncated form of CREB-binding protein (CBP) exhibit deficits in hippocampal synaptic plasticity and memory storage. Learn Mem 2005;12:111-119.
80. Wood MA, Hawk JD, Abel T. Combinatorial chromatin modifications and memory storage: a code for memory? Learn Mem 2006;13:241-244.

81. Oliveira AM, Wood MA, McDonough CB, Abel T. Transgenic mice expressing an inhibitory truncated form of p300 exhibit long-term memory deficits. Learn Mem 2007;14:564-572.

82. Oliveira AM, Estévez MA, Hawk JD, Grimes S, Brindle PK, Abel T. Subregion-specific p300 conditional knock-out mice exhibit long-term memory impairments. Learn Mem 2011;18:161-169.

83. Vecsey CG, Hawk JD, Lattal KM, Stein JM, Fabian SA, Attner MA, et al. Histone deacetylase inhibitors enhance memory and synaptic plasticity via CREB: CBP-dependent transcriptional activation. J Neurosci 2007;27:6128-6140.

84. Barrett RM, Malvaez M, Kramar E, Matheos DP, Arrizon A, Cabrera SM, et al. Hippocampal focal knockout of CBP affects specific histone modifications, long-term potentiation, and long-term memory. Neuropsychopharmacology 2011;36:1545-1556.

85. Valor LM, Pulopulos MM, Jimenez-Minchan M, Olivares R, Lutz B, Barco A. Ablation of CBP in forebrain principal neurons causes modest memory and transcriptional defects and a dramatic reduction of histone acetylation but does not affect cell viability. J Neurosci 2011;31: 1652-1663.

86. Ciocchi S, Herry C, GrenierF, Wolff SB, LetzkusJJ, Vlachos I, et al. Encoding of conditioned fear in central amygdala inhibitory circuits. Nature 2010;468:277-282.

87. Duvarci S, Popa D, Pare D. Central amygdala activity during fear conditioning. J Neurosci 2011;31:289-294.

88. McLaughlin J, Skaggs H, Churchwell J, Powell DA. Medial prefrontal cortex and Pavlovian conditioning: trace versus delay conditioning. Behav Neurosci 2002;116:37-47.

89. Powell DA, Skaggs H, Churchwell J, McLaughlin J. Posttraining lesions of the medial prefrontalcortex impair performance of Pavlovianeyeblink conditioning but have no effect on concomitant heart rate changes in rabbits (Oryctolagus cuniculus). Behav Neurosci 2001;115:1029-1038.

90. Ranjan V, Singh S, Siddiqui SA, Khan MY, Prakash A. Differential histone acetylation in the Amygdala leads to fear memory consolidation and extinction. Int J Sci Tech Soc 2015;1:43-49.

91. George MS, Nahas Z, Borckardt JJ, Anderson B, Foust MJ, Burns C, et al. Brain stimulation for the treatment of psychiatric disorders. Curr Opin Psychiatry 2007;20:250-254; discussion 247-249.

92. Chiba T, Kayahara T, Nakano K. Efferent projections of infralimbic and prelimbic areas of the medial prefrontal cortex in the Japanese monkey, Macaca fuscata. Brain Res 2001;888:83-101.

93. Hurley KM, Herbert H, Moga MM, Saper CB. Efferent projections of the infralimbic cortex of the rat. J Comp Neurol 1991;308:249-276.

94. Room P, Russchen FT, Groenewegen HJ, Lohman AH. Efferent connections of the prelimbic (area 32) and the infralimbic (area 25) cortices: an anterograde tracing study in the cat. J Comp Neurol 1985;242:40-55. 